\title{
Research on the Teaching Reform of Pharmacology Course under the Background of Transformation
}

\author{
Huijie Chen ${ }^{a}$, Lei Diaob \\ College of Pharmaceutical Engineering, Jilin Agriculture Science and Technology University, Jilin, \\ 132101, China \\ achenhuijie1983@163.com, b56179115@qq.com
}

Keywords: Pharmacology, Teaching Reform, Pharmacy Major, Transformational Development

\begin{abstract}
At present, the transformation and development puts forward new requirements for the application-oriented talent training mode of local undergraduate colleges. In order to adapt to the new talent training model, professional curriculum reform is imperative. For the pharmacy professional course "Pharmacology", this paper mainly discusses the design of teaching content, the reform of teaching methods and the innovation of teaching links to adapt to the requirements of transformation and development, and truly play its role in practice.
\end{abstract}

\section{Introduction}

With the advent of higher education and popularization, how to diversify teaching in higher vocational colleges is a new topic that must be faced at present. The course of "Pharmacology" has the disadvantages of paying attention to theory and ignoring practice in normal teaching. There is a certain deviation between the mastery of students' theoretical knowledge and the cultivation of practical ability. As far as colleges and universities are concerned, the cultivation of both talents and talents, as well as the high-skilled and diversified talents of a multi-functional talent, that is, the goal of the employment of the world, determines the importance of teaching in most institutions of higher learning. At present, the Pharmacology of pharmacy in our school is basically the concentration of pharmacology in the medical department. It is far from the training goal and employment goal of the comprehensive quality, practical ability, innovative ability of pharmacy students [1].

Therefore, in view of the above problems, based on the local medical resources, and based on the knowledge module, the curriculum is modularized, and the teaching content is rearranged and combined, which not only integrates the curriculum, but also avoids the division [2], disjoint or repetition of the curriculum. At the same time, the teaching and personnel training objectives are closely linked, and the cultivation of practical ability is emphasized. In the course of teaching, the teachers give full play to the advantage of "double-skilled dual-energy type", that is, "the relative familiarity of the academic circles with the industry", and collaborate with students to innovate [3], truly fit the spirit of transformation and development, and implement the transformation and development. The aim is to improve the teaching level of the college as a whole and cultivate high-quality applied talents [4].

\section{Teaching Content Reform}

\subsection{Focus on Curriculum Content Integration.}

The Pharmacology course is a professional basic course for undergraduate majors in pharmacy. Prerequisite courses include Microbiology, Biochemistry, Human Anatomy and Physiology, and Traditional Chinese Medicine. The follow-up course is mainly Chinese Pharmacology. In the design of teaching content, systematic analysis of the relevant knowledge of the pre-requisite course can not only reach the warmth and know the new, but also avoid repeating the teaching content. 


\subsection{Based on Local Medical Resources.}

In the design of teaching content, teachers should highlight the value and importance of pharmacological research content and technical methods in the development of new drugs and pharmaceutical production, so that students fully realize the medicinal value of the pharmacology course for the development of traditional Chinese medicine resources, and recognize the importance of promoting the development of local medicine economy.

\subsection{Relying on Knowledge Modules.}

In the specific teaching process, the teacher decomposed the course of pharmacology into multiple knowledge modules, including pharmacodynamics and pharmacokinetic modules, neurological pharmacology module, central nervous system pharmacology module, cardiovascular system pharmacology module, endocrine system pharmacology module and chemotherapy drug module. The knowledge module design can not only highlight the drug characteristics of each type of disease, but also connect each knowledge module into a main line. At the same time, clinical rational drug use knowledge can be passed on to students in a holistic way.

\section{Teaching Method Reform}

\subsection{Highlight the Subjective Status of Students.}

In the arrangement of the teaching content, the students are assigned homework in advance, and the students can combine the content of the class with the extracurricular preparation through pre-study and learning with problems [5].

\subsection{Make Full Use of Laboratory Resources.}

Pharmacology is a combination of theory and practice. In addition to the interaction with the theoretical knowledge points, the experimental project still needs to combine laboratory resources. In the teaching process, the teacher should design a number of experimental projects such as cardiovascular system drugs, anti-inflammatory drugs, nervous system drugs and analgesic drugs, which will effectively consolidate and confirm the theoretical knowledge and make efficient use of laboratory teaching resources [6].

\subsection{Focus on Situational Teaching.}

The content of the Pharmacology course covers a wide variety of drugs, and some of them can be used to simulate pharmacy scenarios. According to the teaching progress, teachers can choose the common diseases or symptoms such as fever, headache, diarrhea, inflammation and cough for situational teaching. Let some students simulate pharmacists, and another part of the students simulate patients. The patients state their own symptoms and signs of the disease. The pharmacist summarizes the information provided by the patient, combines the knowledge learned, recommends the use of appropriate drugs, and prescribes the precautions for patients [7].

\subsection{Play the Guiding Role of Industry Enterprises.}

Pharmaceutical production enterprises have higher requirements for practitioners' practical skills, and there is a shortage of high-level pharmaceutical production and research talents. We will cultivate the shortage of talents that meet the needs of the industry, strengthen the cooperation between schools and enterprises, and then reflect the purpose of local colleges and universities to serve the localities. In the course of teaching, the teachers should make full use of the good school-enterprise cooperation relationship, and hire industry experts from Jilin enterprises to enter the classroom to conduct targeted academic lectures and skills training for students. This enables students to adapt to the corporate environment as soon as possible after employment [8].

\subsection{Play the Role of Double Teacher and Dual-Energy Teacher.}

The instructors of this course should have licensed pharmacists and practicing Chinese 
pharmacists certificates, and have long practiced in hospital pharmacies and pharmaceutical manufacturing enterprises. They have rich experience in the industry and are familiar with the technology of hospitals and pharmaceutical companies. In the teaching process, teachers should focus on practical teaching content, and pay attention to the timeliness of teaching, and can timely find and adjust the problems in the previous syllabus.

\section{Using a Variety of Learning Methods to Guide}

\subsection{Targeting of Learning Method Guidance.}

Pharmacology plays an important role in professional internships and employment. There are many pharmacy knowledge points and experimental skills that need to be memorized, understood and applied. Therefore, to improve the teaching effect, it is very important to provide students with targeted instruction. In view of the general knowledge of the basic knowledge of pharmacy, students are guided to adopt dialectical thinking learning methods and mapping thinking learning methods. In order to learn the knowledge of drug pharmacology and clinical application in various theories, students are mainly guided by shorthand learning and sleep learning methods. In turn, it is possible to consolidate professional basic knowledge of students and cultivate innovative thinking of students [9].

\subsection{Comprehensive Use of Learning Methods.}

Students are required to write the pharmacology subject review papers and design experimental programs, which reflects the comprehensive application of a variety of learning methods.

\section{Practical Application}

\subsection{Graduation Thesis Topics.}

After completing the course of Pharmacology, students will combine the cardiovascular pharmacology, antibacterial pharmacology, endocrine pharmacology, neuropharmacology and other related knowledge systems to select topics and study design, and carry out innovative research. The research on graduation thesis highlights the practical application value of pharmacology [10].

\subsection{Professional Employment and Social Feedback.}

After nearly 20 years of development, our pharmacy major has achieved remarkable results in running schools. It has explored a series of talent training models suitable for local economic and social development, especially in the school-enterprise cooperation and the integration of production and education. Under the background of application transformation, after the teaching reform of the course of pharmacology, the graduates trained are more suitable for local economic and social needs. After mastering the theoretical knowledge and experimental skills of pharmacology, students can be employed in new drug research and development departments, pharmaceutical pharmacies, and research institutes of pharmaceutical companies, and can apply the knowledge of innovation to work, and explore the basis of pharmacodynamics and pharmacy management work. Throughout the teaching process, teachers explore the design of teaching content, the reform of teaching methods and the innovation in teaching links.

\section{Conclusion}

In this paper, the teaching reform of the pharmacology course is based on local medical resources and based on the knowledge module. The curriculum is modularized and the teaching content is rearranged and combined, which not only integrates the curriculum, but also avoids the division, disjoint or repetition of the curriculum. It also closely links teaching with the goal of training talents and highlights the cultivation of practical ability. Teachers choose comprehensive practice methods such as simulation pharmacy, experimental operation, and new drug examples, 
and continuously consolidate and strengthen students' learning and application of theoretical knowledge of teaching materials, which will lay a foundation for the cultivation of applied talents.

\section{References}

[1] Rong Zeng, Zhiqi Wang, Jin Zhou, et al. Discussion on Innovative Talents Training Mode in Chinese Medicine Pharmacology Teaching [J]. Pharmaceutical education, 2013, 29(2): 15-17.

[2] Junlin Yu, Yanwu Hu, Liqiu Zhang. Discussion on the Construction Mode of Practical Teaching Base in Pharmaceutical Specialty [J]. Journal of tonghua normal university, 2014, 35(3): 85-86.

[3] Ji Ya. Exploration and Practice of School-based Curriculum Reform under the Background of Transformation and Development [J]. Journal of Hulunbeier University, 2017, 25(3): 105-108.

[4] Yanwu Hu, Xiaoyan He, Zijing Wu, et al. Research on Teaching Reform of Pharmacology undergraduate Course in Local Universities under the Background of Applied Transformation [J]. China health industry, 2017. 115-116.

[5] Changqing Hong. Exploration on the Teaching Reform of Pharmacology Course Based on Strengthening the Role of Students [J]. Strait science, 2013, (12): 95-96.

[6] Xinwu Huang, Yuxia Xiong, Hua Li, et al. Experience in exploratory pharmacology experiment teaching [J]. Basic Medical Education, 2013, 15(4): 384-386.

[7] Xiaohong Zhang, Yanli Gao, Pengfei Ren, et al. Preliminary Study on the Practice of Simulated Pharmacy in the Teaching Reform of Pharmacology[J]. Guide of china medicine, 2014, 12(8):235.

[8] Wei Wu, Yali Ren, Jian Gu. The current situation and analysis of the development of pharmacology course in school - enterprise Cooperation [J]. Public Medical Forum Magazine, 2018, 22(2): 252-253.

[9] Rong Zeng, Zhiqi Wang, Ke Du. et al. The Exploration of Teaching Reform on the Course the Monograph in Pharmacology of Traditional Chinese Medicine to Develop the Innovative Ability of Graduate Students [J]. Journal of Hunan Univ. of CM, 2016, 36(10): 103-105.

[10] Min Chen, Mingsheng Zhang, Yan Wang, et al. Discussion on the Reform of Pharmacology Experiment Teaching Based on the Cultivation of Students' Scientific Research Interests[J]. Basic Medical Education, 2015, 17(1): 52-53. 